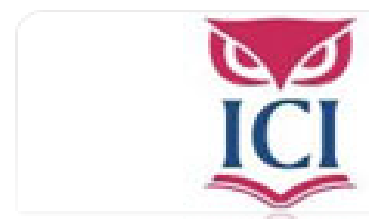

IUS. Revista del Instituto de Ciencias Jurídicas de Puebla A.C.

ISSN: $1870-2147$

revista.ius@hotmail.com

Instituto de Ciencias Jurídicas de Puebla A. C.

México

Requejo Rodríguez, Paloma

La reforma constitucional del modelo de organización territorial español en el informe del consejo de estado de 16 de febrero de 2006

IUS. Revista del Instituto de Ciencias Jurídicas de Puebla A.C., núm. 21, 2008, pp. 159-167 Instituto de Ciencias Jurídicas de Puebla A. C.

Puebla, México 


\section{LA REFORMA CONSTITUCIONAL DEL MODELO DE ORGANIZACIÓN TERRITORIAL ESPAÑOL EN EL INFORME DEL CONSEJO DE ESTADO DE 16 DE FEBRERO DE 2006}

Paloma Requejo Rodríguez*

1. Introducción

2. El alcance de la reforma

3. El contenido de la reforma

4. Otros contenidos posibles

5. Conclusión

\section{RESUMEN}

El presente artículo expone y analiza las propuestas formuladas por el Consejo de Estado español, en respuesta a la consulta elevada por el Gobierno sobre su intención de introducir en la Constitución la denominación de las Comunidades y Ciudades Autónomas que forman el Estado de las autonomías, con el objeto de dar por cerradas algunas de las manifestaciones del principio dispositivo característico de esta estructura territorial.

\section{ABSTRACT}

The present articulates it exposes and it analyzes the proposals formulated by the Council of Spanish State, in answer to the consultation risen by the Government on its intention of introducing in the Constitution the denomination of the Communities and autonomous Cities that form the State of the autonomies, in order to giving for closed some of the manifestations of the principle characteristic device of this territorial structure.

\section{INTRODUCCIÓN}

Hace ya cinco años tuve el honor de participar en el número doce de esta publicación con un trabajo titulado "La organización territorial del Estado en la Constitución española de 1978”. El vaticinio con el que concluía mi colaboración, en el que, tras constatar las continuas polémicas que rodeaban y rodean al llamado Estado autonómico español, aventuraba que este

* Doctora en derecho, profesora titular de derecho constitucional, Universidad de Oviedo (España). 
modelo, lejos de ser definitivo, estaba llamado a ser superado o al menos perfeccionado, parece cumplirse a través de diferentes procedimientos, no siempre lícitos. En efecto, en este tiempo, ante la dificultad de lograr las mayorías cualificadas exigidas para que prospere una revisión constitucional, se ha empezado a construir la casa por el tejado, anticipándose las reformas de los estatutos de varias comunidades a la de la propia Constitución. A través de procedimientos complejos, pero con mayorías menos agravadas que las previstas en el título x de la Constitución española ( $\mathrm{CE}$ ) para modificar la norma suprema, se ha pretendiendo introducir en los nuevos estatutos desde propuestas inequívocamente inconstitucionales, como la que se impulsó desde el País Vasco y fue rechazada por el Congreso de los Diputados, ${ }^{1}$ a otras de dudosa constitucionalidad, que fueron pulidas en su paso por las cámaras, sin que ello impidiera que algunas de ellas ya vigentes, como la catalana, se encuentren a la espera de pronunciamiento por parte del Tribunal Constitucional sobre su validez. A otro ritmo, mucho más lento que el de las iniciativas autonómicas, el gobierno estatal sugiere una reforma constitucional que afecta a cuestiones varias, desde la modificación del orden sucesorio a la Corona, a la inclusión de una referencia a la pertenencia de España a la Unión Europea, pasando por la potenciación del Senado como Cámara de representación territorial o, en lo que a nosotros nos interesa, la incorporación al texto constitucional de la denominación de las Comunidades y Ciudades Autónomas. En todos los aspectos mencionados la propuesta del Gobierno, si es que cabe denominarla así, no puede ser más genérica, por lo que será el Consejo de Estado, su órgano supremo consultivo, quien a instancia del propio Gobierno concrete en un informe de 16 de febrero de $2006^{2}$ las diferentes alternativas existentes para llevar a cabo una reforma constitucional como la que se pretende y que, no olvidemos, requeriría para salir adelante el apoyo del principal partido de la oposición, lo que hoy por hoy parece imposible; de ahí la paralización del proceso. A analizar someramente las principales recomendaciones del Consejo de Estado en esta materia dedicaremos las

${ }^{1}$ Recordemos que los estatutos de autonomía no sólo son norma institucional básica de la Comunidad Autónoma, sino también ley orgánica del Estado, por lo que su reforma siempre ha de ser aprobada tanto en el Parlamento autonómico como luego en las Cortes Generales, sin perjuicio de que además en ciertos casos deba ser sometida a referéndum en la Comunidad Autónoma de que se trate.

${ }^{2}$ El informe puede consultarse en la propia página web del Consejo de Estado (www.consejo-estado. es) o en la obra "El informe del Consejo de Estado sobre la reforma constitucional: texto del informe y debates académicos”, Edición a cargo de Francisco Rubio Llorente y José Álvarez Junco; Eliseo Aja... et al., Consejo de Estado, Centro de Estudios Políticos y Constitucionales, Madrid, 2006, en la que también puede encontrarse un interesante debate doctrinal sobre el particular. 
páginas que siguen, por su interés en lo que tienen de indicativas de la dirección que puede tomar una futura reforma constitucional del modelo descentralizado español.

\section{El alcance de la reforma}

Lo primero que sorprende de la propuesta gubernamental es su aparente falta de ambición. Ofrecer como respuesta a las críticas que merece el Estado autonómico o, al menos, su funcionamiento, tan sólo la inclusión en el texto constitucional del catálogo de Comunidades y Ciudades Autónomas que lo integran, parece claramente insatisfactorio y nada novedoso sobre lo ya conocido, viniendo a constatar tan sólo lo que es una realidad. Sin embargo, como pone de manifiesto el Consejo de Estado, esta pretensión tiene mayor calado, pues, además de reflejar la consolidación del Estado de las autonomías, busca "superar la apertura que la propia Constitución ha introducido en la organización territorial a través del principio dispositivo". La reforma es, por tanto, más compleja de lo que se creía, ya que elimina no todas pero sí algunas de las manifestaciones del principio dispositivo, especialmente aquellas que tuvieron lugar en los primeros momentos, rasgo señero hasta ahora de nuestro modelo, en tanto la Constitución no impone la existencia de Comunidades Autónomas, sino que tan sólo prevé como posibilidad su formación; de ahí que no se indicara ni su número, ni su denominación, ni las competencias que debían asumir. Esta superación del principio dispositivo es valorada positivamente por el Consejo de Estado, al considerar que en unos casos la potencialidad que parecía asegurar ha quedado en nada por la firma de pactos autonómicos y la emulación competencial entre Comunidades Autónomas, y que en otros su presencia al hilo de las reformas estatutarias no ha dado más que problemas, cuando, a nuestro entender, lo cierto es que si el principio dispositivo no ha funcionado no ha sido a causa de su configuración constitucional, sino de los abusos y distorsiones provocadas en su concreta aplicación por partidos políticos y Comunidades Autónomas.

\section{El CONTENIDO dE LA REFORMA}

Como hemos reiterado, el contenido de la reforma se limita a incluir un listado de las Comunidades y las Ciudades Autónomas. Ello obliga al Consejo de Estado a precisar el criterio con base al cual se realizará la enumeración, 
la denominación más adecuada que recibirán los territorios que en ella aparezcan y el lugar en el que se debe ubicar en el texto constitucional.

A la hora de determinar qué criterio se considera más idóneo para ordenar la enumeración de las Comunidades Autónomas, el Consejo de Estado se decanta por el criterio histórico-cronológico, es decir, por atender al orden de creación de las distintas Comunidades, lo cual no deja de sorprender, si pensamos que, como el propio Consejo señala, el criterio alfabético es el mayoritario en la historia constitucional española y en el derecho comparado y, sobre todo, que la reforma quiere superar un momento inicial de aplicación del principio dispositivo que el criterio cronológico no hace más que recordar.

En cuanto a la denominación, descartadas las denominaciones oficiales para no dificultar una futura reforma estatutaria de las mismas ${ }^{3}$ y el empleo de los términos nacionalidad o región en tanto sólo caracterizan el sustrato social de la Comunidad Autónoma, se propone incluir en castellano y en otras lenguas oficiales, si procede, los nombres de uso común por los que las Comunidades son conocidas, conservando tan sólo Valencia y Navarra sus denominaciones oficiales de Comunidad Valenciana y de Comunidad foral de Navarra, bien por ser fruto de una difícil transacción, bien por su repercusión jurídica.

Respecto de la ubicación del listado, no es un tema baladí, pues conlleva consecuencias políticas y jurídicas, ya que del lugar depende la relevancia que se quiera dar a las Comunidades Autónomas y el procedimiento de reforma que se ha de seguir.

Aunque el Consejo de Estado ofrece varias alternativas, no es menos cierto que parece decantarse por una, en tanto va señalando las deficiencias de las demás. Así propone que la reforma no sólo alcance a los artículos 137 y 143 del título vIII CE, sino también que haya una mención a la misma en el propio Art. 2 del título preliminar, puesto que circunscribirla al título vIII no subrayaría la naturaleza del Estado de las autonomías como principio estructural básico y diluiría el papel de las Comunidades, equiparándolo al de otros entes territoriales que la Constitución contempla, como los municipios y las provincias.

Por este motivo sugiere, como indicamos, una reforma agravada, si-

${ }^{3}$ El Art. 147 CE establece que la denominación oficial de la Comunidad Autónoma vendrá fijada en el Estatuto de Autonomía. Si la misma apareciera también en el texto constitucional y la Comunidad Autónoma quisiera alterarla, ello exigiría reformar la Constitución. Por ello, se aconseja que tras el listado constitucional de Comunidades Autónomas se precise que su denominación oficial es la estatutaria. 
guiendo el procedimiento previsto en el Art. $168 \mathrm{CE}$, que afecte en primer lugar al tenor del Art. 2 CE y luego a los Arts. 137 y 143 CE.

El Art. 2 pasaría a afirmar que "la Constitución se fundamenta en la indisoluble unidad de la Nación española, patria común e indivisible de todos los españoles, y reconoce y garantiza la autonomía de las nacionalidades y regiones que la integran, constituidas en Comunidades Autónomas, así como la solidaridad entre todas ellas". El cambio principal radica, entonces, en transformar lo que era un derecho a la autonomía de nacionalidades y regiones, en tanto ya se ejerció, en una garantía constitucional de la autonomía, aunque, a nuestro juicio, no hubiera estado de más haber destacado la vertiente político-organizativa del precepto, contraponiendo en él tan sólo Estado a Comunidades Autónomas y no Nación-soberanía a nacionalidades/regiones-autonomía, lo que podría haberse reconducido al Art. 1.2 CE.

Para los Arts. 137 y 143 CE se proponen dos soluciones que conllevan una menor o mayor modificación de lo existente. El Consejo parece optar en su argumentación por la de mayor profundidad, ${ }^{4}$ en la que el Art. 137, otorgando protagonismo a las Comunidades y diferenciando su autonomía del de otros entes territoriales sin acudir a la siempre polémica contraposición entre autonomía política-autonomía administrativa, pasaría a decir “1. España se organiza territorialmente en Comunidades Autónomas y Ciudades Autónomas, así como en municipios y provincias. 2. Las Comunidades y Ciudades Autónomas gozan de autonomía en los términos previstos por la Constitución y los respectivos Estatutos. La ley asegurará la autonomía de municipios y provincias para la gestión de sus respectivos intereses." Por su parte, el Art. 143 CE, reflejando que la descentralización no busca tan sólo satisfacer aspiraciones territoriales sino que es un principio básico de la organización territorial, añadiría que "1. Para realizar el derecho de nacionalidades y regiones a gozar de autonomía en la gestión de sus respectivos intereses, asegurar la solidaridad entre ellas y hacer más eficaz la acción de los poderes públicos, España se organiza territo-

\footnotetext{
${ }^{4}$ Con la más sencilla el Art. 137 cE pasaría a decir: "España se organiza territorialmente en municipios, provincias, Comunidades Autónomas y Ciudades Autónomas. Todas estas entidades gozan de autonomía para la gestión de sus respectivos intereses." Y el Art. 143 señalaría que: "1. Son Comunidades Autónomas: País Vasco/Euskadi, Cataluña/Catalunya, etc.; 2. Las denominaciones oficiales de estas Comunidades son las establecidas en sus respectivos Estatutos; 3. Son ciudades Autónomas Ceuta y Melilla." Sin embargo, se critica la equiparación que esta redacción realiza entre Comunidades Autónomas, provincias y municipios y entre la autonomía de la que gozan unos y otros, así como la desvinculación de las Comunidades Autónomas de las nacionalidades y regiones que le sirven de apoyo.
} 
rialmente en las siguientes Comunidades Autónomas: País Vasco/Euskadi, Cataluña/Catalunya, etc.; 2. Las denominaciones oficiales de estas Comunidades son las establecidas en sus respectivos Estatutos; 3. Son ciudades Autónomas Ceuta y Melilla."

Indudablemente aunque éste es el núcleo de la reforma, el Consejo de Estado es consciente de que la misma afectará directamente a otros preceptos, que pueden entrar en contradicción con ella o verse vaciados de contenido, por ejemplo, los Arts. 144, 146, 148 y 151 cE, respecto del acceso a la autonomía, la aprobación estatutaria y la asunción competencial en una primera fase ya superada o, en la misma línea, las disposiciones transitorias $1^{\text {a }}$ a $5^{\mathrm{a}} \mathrm{CE}$. Pero también el Consejo alude a otras disposiciones constitucionales que, si bien son plenamente compatibles con la revisión proyectada, ésta puede servir de coartada para introducir en ellas algunas mejoras. Es precisamente esta parte del informe la más sugerente, pues, aunque el Consejo de Estado no ofrece redacciones alternativas, al tratarse de aspectos que no son en puridad objeto de consulta, sí apunta qué cuestiones son las más significativas y qué reformas pueden contribuir a intentar mejorar realmente el funcionamiento del Estado autonómico.

\section{Otros CONTENIDOS POSIBLES}

A juicio del Consejo de Estado principios tan capitales para el Estado autonómico como los de solidaridad, igualdad, cooperación y colaboración deben ser revisados. Las carencias actuales en la regulación de un principio como el de solidaridad, clave a su entender para el equilibrio entre unidad y autonomía, se han venido superando gracias a la jurisprudencia del Tribunal Constitucional; sin embargo, resulta necesario que constitucionalmente se precisen sus destinatarios, los deberes que conlleva y las consecuencias que se derivan de su infracción. También la reforma podría aclarar algunos asuntos que afectan a la igualdad, como el sentido de la prohibición contenida en el vigente Art. 138.2 cE de que las diferencias estatutarias puedan implicar privilegios económicos y sociales o si el Estado debería asegurar un nivel mínimo de servicios en toda España en el ámbito de los derechos económicos y sociales, sin impedir que las Comunidades puedan conferir más derechos que los que se disfrutan en otras. Igualmente la Constitución debiera acoger de manera expresa deberes como los de cooperación y colaboración horizontal y vertical entre entes territoriales, hasta ahora presentes en la jurisprudencia, y concretar sus manifestaciones. 
En otro orden de cosas, necesario sería también reestructurar las referencias constitucionales a la provincia, actualizando su naturaleza y funciones, pasando a ser considerada como una "división territorial para la organización y funcionamiento de la Administración general del Estado", más que a ser vista como entidad local con personalidad y autonomía, lo que complica de modo excesivo la organización del Estado.

Como hemos puesto de manifiesto, el rasgo más destacable del modelo español de organización territorial es sin duda alguna su apertura. Una apertura conseguida, de una parte, por las diversas expresiones del principio dispositivo y, de otra, por la llamada que la propia Constitución realiza en su Art. 150 a unas normas infralegales que permitirán alterar el reparto de competencias entre Estado y Comunidades Autónomas. Si bien, como se ha ido señalando, las manifestaciones del principio dispositivo sufrirían una considerable rebaja si llegara a aprobarse la reforma propuesta, otras, aquellas que tienen lugar más allá del momento inicial de la constitución del Estado autonómico, perviven y pueden ser sustancialmente mejoradas. Nos estamos refiriendo a la regulación de la reforma de los estatutos de autonomía, hoy por hoy de gran complejidad por diversos motivos, desde la dispersión de las normas que lo regulan, hasta la diversidad de procedimientos existentes según la vía que se hubiera elegido para acceder a la autonomía y el contenido de aquello que se quiera modificar. Por estos motivos el Consejo de Estado propone en cuanto a la reforma estatutaria, de un lado, que el procedimiento aparezca regulado en lo esencial en la Constitución y en el detalle en los reglamentos parlamentarios y, de otro, una simplificación de los procedimientos, reducidos a dos en atención a si la revisión afecta a la organización interna de la Comunidad Autónoma o a la delimitación competencial y al ejercicio de derechos. En el primer caso, el Consejo sugiere la desaparición de la aprobación de la reforma por ley orgánica, siendo suficiente que las Cortes autoricen, tan pronto la reforma sea aprobada por el Parlamento autonómico, la celebración de referéndum. En el segundo, también aconseja eliminar la aprobación de la reforma por ley orgánica, para evitar las confusiones que puede generar en las relaciones entre normas el hecho de que el estatuto tenga ese carácter, pasando a ser aprobado conforme al procedimiento previsto en el Art. 74 $\mathrm{CE}$, que exige mayoría de cada Cámara, ${ }^{5}$ sin que se descarte la posibilidad,

\footnotetext{
${ }^{5}$ De no existir acuerdo entre Congreso y Senado, "se intentará obtener por una Comisión Mixta compuesta de igual número de Diputados y Senadores. La Comisión presentará un texto, que será votado por ambas Cámaras. Si no se aprueba en la forma establecida, decidirá el Congreso por mayoría absoluta."
} 
a nuestro entender altamente recomendable, de agravar las mayorías a las que se refiere este precepto. Por último, se quiere reforzar el control de constitucionalidad al que se someten los estatutos de autonomía, introduciendo, junto al actual control del Tribunal Constitucional que opera una vez que la reforma ya está en vigor, un recurso previo de constitucionalidad ante el mismo órgano, que le permita atajar los vicios en los que pudiera incurrir antes de su entrada en el ordenamiento. No obstante, un recurso de este tipo ya estuvo vigente en nuestro ordenamiento y se derogó por su utilización abusiva por la oposición como mecanismo de obstrucción parlamentaria.

Pero, como hemos indicado, la apertura constitucional sigue estando presente, por mucho que vía estatutaria se hayan asumido las máximas competencias posibles, a través de las leyes previstas en el Art. 150 CE, especialmente en su apartado 2, que permite al Estado transferir a favor de las Comunidades competencias estatales susceptibles de tal delegación. Sobre este precepto han surgido diferentes dudas interpretativas sobre la naturaleza y alcance de lo transferido, en muchos casos ya disipadas por la doctrina y la jurisprudencia, que el Consejo de Estado considera adecuado clarificar en el texto constitucional, especialmente lo que atañe al objeto de la transferencia o delegación, esto es, el ejercicio de competencias que no estén vinculadas al concepto de soberanía, no resulten indispensables para el correcto funcionamiento de la organización general del Estado, no pongan en riesgo el indirizzo político del Gobierno en materias de su exclusiva competencia o no tengan nada que ver con lo básico, así como al fin que justifica la transferencia, que no es otro que contribuir a que las Comunidades ejerzan más eficazmente sus competencias estatutarias.

\section{Conclusión}

Rico en propuestas y estéril en resultados es el panorama que no sólo podemos describir por el momento, sino el que presumiblemente se avecina en el futuro más inmediato. Habrá que esperar, al menos, a la cita electoral del próximo año para ver cuál es el curso de los acontecimientos, pero hoy por hoy la reforma constitucional está bloqueada. El procedimiento agravado previsto en el Art. 168 CE es el que se ha de seguir para revisar los preceptos analizados. La mayoría de $2 / 3$ en el Congreso y en el Senado, indispensable para que la reforma salga adelante, sin olvidar su posterior ratificación en referéndum, dificulta en gran medida el éxito de la inicia- 
tiva, pues obliga a que el partido mayoritario y el principal partido de la oposición se pongan de acuerdo sobre la oportunidad y los términos de la reforma. Si bien el consenso parece posible en lo atinente a la revisión del orden sucesorio a la Corona, que permitiría heredar al primogénito con independencia de cual sea su sexo, las diferencias resultan en la actualidad irreconciliables en lo que respecta a los cambios que afectan al modelo de organización territorial y al papel que el Senado está llamado a jugar en un Estado descentralizado. Pero más allá de desencuentros políticos, el valor jurídico y la utilidad del informe del Consejo de Estado comentado están fuera de toda duda, en tanto ha contribuido a impulsar y canalizar un debate sobre propuestas, gracias a él, concretas y fundadas, que tarde o temprano acabarán siendo una realidad. 